This authors' personal copy may not be publicly or systematically copied or distributed, or posted on the Open Web, except with written permission of the copyright holder(s). It may be distributed to interested individuals on request.

\title{
Identification, molecular and phylogenetic analysis of poxvirus in skin lesions of southern right whale
}

\author{
Carla Fiorito ${ }^{1,2}$, Carlos Palacios ${ }^{3,4}$, Marcelo Golemba ${ }^{5}$, Ana Bratanich ${ }^{3}$, \\ Maria Belen Argüelles ${ }^{1}$, Ana Fazio ${ }^{1}$, Marcelo Bertellotti ${ }^{1}$, Daniel Lombardo ${ }^{2, *}$ \\ ${ }^{1}$ Laboratorio de Ecofisiología Aplicada al Manejo y Conservación, Centro Nacional Patagónico, CONICET, \\ 9120 Puerto Madryn, Chubut, Argentina
}

${ }^{2}$ Laboratorio de Histología, Facultad de Ciencias Veterinarias, Universidad de Buenos Aires, C1427CWO Buenos Aires, Argentina

${ }^{3}$ Laboratorio de Virología, Facultad de Ciencias Veterinarias, Universidad de Buenos Aires, C1427CWO Buenos Aires, Argentina

${ }^{4}$ Centro de Virología Animal, Instituto de Ciencia y Tecnología Dr. Cesar Milstein, CONICET, C1440FFX Buenos Aires, Argentina

${ }^{5}$ Laboratorio de Biología Celular y Retrovirus, Hospital de Pediatría S.A.M.I.C. 'Prof. Dr. Juan P. Garrahan', C1245AAM Buenos Aires, Argentina

\begin{abstract}
Poxvirus skin disease has been reported in several species of cetaceans, principally in odontocetes, and a single report in mysticetes. Southern right whales Eubalaena australis in Peninsula Valdes, Argentina, show a variety of skin lesions of unknown etiology, and the number of these lesions has increased in recent years. Samples from dead whales were taken in order to establish the etiology of these lesions. One calf and one adult presented ring-type lesions, characterized by a circumscribed and slightly raised area of skin. Lesions were histologically characterized by the presence of microvesicles and vacuolated cells in the stratum spinosum, along with hyperplasia of the stratum corneum and eosinophilic inclusion bodies in the cytoplasm of the epithelial cells. Transmission electron microscopy showed aggregations of virions with typical poxvirus morphology. PCR of cetacean poxvirus (CPV) DNA polymerase, DNA topoisomerase I and parapoxvirus DNA polymerase gene fragments was done, and confirmed the presence of poxvirus in one sample. Phylogenetic analysis showed that the detected poxvirus belongs to the CPV-2 group. This is the first confirmed report of poxvirus in southern right whales in Argentina.
\end{abstract}

KEY WORDS: Cetacean poxvirus $\cdot$ Skin disease $\cdot$ Southern right whale $\cdot$ Eubalaena australis

\section{INTRODUCTION}

Cetacean poxvirus (CPV) has been reported in several free-ranging cetacean species, including Delphinidae, Phocoenidae, Ziphiidae and Balaenidae, as well as in captive Tursiops truncatus and T. aduncus (Geraci et al. 1979, Baker 1992, Van Bressem et al. 1993, 1999, 2009, Bracht et al. 2006, Blacklaws et al. 2013). Poxvirus was identified in 2 sets of lesions, one of them characterized by pinhole or ring-like lesions, flat or slightly raised, which appear as solitary or coalesced circular gray blemishes (Geraci et al. 1979). The other is referred to as tattoo skin disease (TSD), characterized by irregular, gray, black or yellowish and stippled lesions (Van Bressem et al. 2009).

Poxvirus skin disease (PSD) is caused by 2 newly suggested members of the Poxviridae family, CPV-1 and CPV-2, possibly belonging to an unassigned 
genus within the Chordopoxvirinae subfamily (Bracht et al. 2006). These viruses are cetacean-specific, and while CPV-1 has been found infecting free-ranging and captive odontocetes from the USA, UK and Asia, CPV-2 was detected infecting a bowhead whale Balaena mysticetus from Alaska (Bracht et al. 2006, Blacklaws et al. 2013).

Epidermal diseases are among the most commonly reported categories of disease in cetaceans, possibly due to the fact that they are often highly visible (Wilson et al. 1999, Hamilton \& Marx 2005). Many cases of PSD in odontocetes have recently been reported, where the lesions are typical and readily distinguished macroscopically (Van Bressem et al. 2009), which makes it possible to study the disease in free populations using photographic material. In addition, the large number of samples facilitates viral DNA characterization and phylogenetic relationships between CPV-1 and other Chordopoxvirinae. In mysticetes, however, information on PSD is limited.

Southern right whales Eubalaena australis at Peninsula Valdes, Argentina show a variety of skin lesions, some of them caused by attacks from kelp gulls Larus dominicanus, which feed on the skin and blubber they tear off from the whales' backs (Rowntree et al. 1998, Fazio et al. 2012, 2015). A variety of other lesions of unknown etiology have been observed, affecting both adults and calves born in this area (Bertellotti et al. unpubl. rep.).

In this study, we aim to report, for the first time and to the best of our knowledge, the presence of poxvirus in skin lesions in southern right whales. A detailed description of the pathology associated with poxvirus infection, direct identification by transmission electron microscopy (TEM) and DNA-based phylogenetic analysis are presented.

\section{MATERIALS AND METHODS}

\section{Sample collection and histopathology}

Skin samples were collected from 12 stranded southern right whales (11 calves and only 1 adult) during the 2012 and 2013 calving seasons along the coast of Peninsula Valdes, Chubut, Argentina. Only stranded whales with a minimum level of post mortem decomposition were sampled (code 2/3; Geraci \& Lounsbury 2005). Two whales, 1 male calf (BFA04/12) and 1 female adult (BFA-01/13), presented a single ring-type lesion at the ventral surface of the left fluke and at the ventral surface of the right pectoral fin respectively. No other lesions were detected in either of these 2 individuals. Both lesions were first photographed, measured, and finally samples were collected for further analysis.

Each sample was split to retain a portion at $-20^{\circ} \mathrm{C}$ for further analysis, while the remainder was fixed in $10 \%$ buffer formalin and processed for histopathological diagnosis according to routine histological procedures. Five-micron thick paraffin sections were cut from each block, mounted on glass slides, deparaffinated and rehydrated, and stained with hematoxylin and eosin. The sections were examined using a binocular brightfield microscope (DM 4000B LED, Leica Microsystems), using a digital camera to capture high-resolution images (DFC 310X, Leica).

\section{TEM}

Tissue sections showing lesions consistent with poxvirus infection were processed for TEM analysis. Samples fixed in $10 \%$ paraformaldehyde were post fixed with $1 \%$ osmium tetroxide. Then, samples were dehydrated in a solution of increasing ethanol concentrations, and embedded in Epon resin. Ultrathin sections $(50-60 \mathrm{~nm})$ were cut with a Reichert-Jung Super Nova (Leica Microsystems) ultra-microtome, mounted on copper 200-mesh grids, double stained with $2 \%$ uranyl acetate and $1 \%$ lead citrate and examined in a JEM 1200 EX II electron microscope (JEOL Ltd.) equipped with an ES1000W Erlangshen CCD Camera (Gatan).

\section{DNA extraction and PCR amplification}

A frozen skin lesion sample (100 ng) was macerated in liquid nitrogen, and total DNA was extracted and purified using DNAzol reagent (Invitrogen). PCRs were carried out in a reaction containing $50 \mathrm{ng}$ of purified DNA, using Platinum ${ }^{\circledR}$ PfX DNA Polymerase (Invitrogen), following the manufacturer's instructions. The amplification conditions were $94^{\circ} \mathrm{C}$

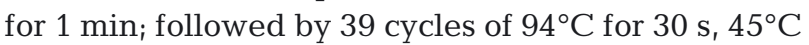
for $30 \mathrm{~s}$ and $68^{\circ} \mathrm{C}$ for $30 \mathrm{~s}$. Primers targeting CPV DNA polymerase, DNA topoisomerase I gene fragments (546 bp and 344 bp respectively), and parapoxvirus DNA polymerase fragment (536 bp) were used as previously described (Bracht et al. 2006). The housekeeping PCR assay was used to indicate the presence of Eubalaena australis DNA and therefore its suitability for use in more specific PCR assays. To assess this, sense 5'-TAC GAG CAG TAG CAC AAA CAA-3' (positions 3163-3183) and antisense 5'-TTA 
CGT TTG AGG GGG GAT GC-3' (positions 37033722) primers were designed to amplify a fragment (560 bp) of the NADH dehydrogenase subunit 1 (ND1) gene (GenBank accession no. AP006473.1). PCR conditions were similar to the ones described earlier in this paragraph, except for the annealing temperature, which was $55^{\circ} \mathrm{C}$.

Amplicons were purified from agarose gel, using a commercial kit (Promega). DNA polymerase and topoisomerase I gene fragments were sequenced twice in each direction, and primer sequence regions were eliminated before performing further analysis. All the resulting chromatograms were analyzed, and presented well-defined peaks and low background noise in the data.

\section{Phylogenetic analysis}

Evolutionary relationships between reference (Blacklaws et al. 2013) and obtained sequences were evaluated by means of separate and concatenated datasets, using DNA polymerase and DNA topoisomerase I sequences. Phylogenetic trees were constructed using nucleotide sequences from predicted amino acid alignments, using the ClustalW option in BioEdit v.7.2.5 software (Hall 1999). Phylogenetic analyses were performed using distance neighborjoining (NJ) and maximum likelihood (ML) methods with MEGA v.6.0 software (Tamura et al. 2013). Bayesian analysis was performed using MrBayes software implemented in the CIPRES Science Gateway server (Miller et al. 2010). The evolutionary model General Time Reversible (GTR), Gamma distribution (G), and proportion of invariable sites (I), was inferred according to Akaike Information Criterion (AIC) statistics, obtained with the jModelTest v0.1.1 software (Posada 2008). The evolutionary model was inferred according to Akaike information criterion (AIC) statistics, obtained with jModelTest v.0.1.1 software (Posada 2008). The robustness of the reconstructed phylogeny (NJ and ML methods) was evaluated by bootstrap analysis and posterior probability for Bayesian analysis, respectively.

\section{Nucleotide sequence accession numbers}

The nucleotide sequences reported in this study were submitted to GenBank and assigned accession numbers KM000064 and KM000065, for the DNA polymerase and DNA topoisomerase I sequences, respectively.

\section{RESULTS}

Although both samples were suitable for histopathology, the autolytic level of the BFA-01/13 sample was an impediment for TEM, but not for PCR assay. For the frozen samples from BFA-04/12 the cold chain was interrupted, rendering them unsuitable for PCR. PCR amplification from formalinized BFA-04/12 samples failed, probably due to degradation of nucleic acids by the fixation process.

\section{Anatomopathological and histological description}

The skin lesions from both whales were a ring-type lesion with a raised center and with no modification of the surface color. The lesions differed in size: the BFA-04/12 lesion was $8 \times 6 \mathrm{~cm}$, and the BFA-01/13 lesion was $3.5 \times 3.5 \mathrm{~cm}$ (Fig. 1). Histological findings

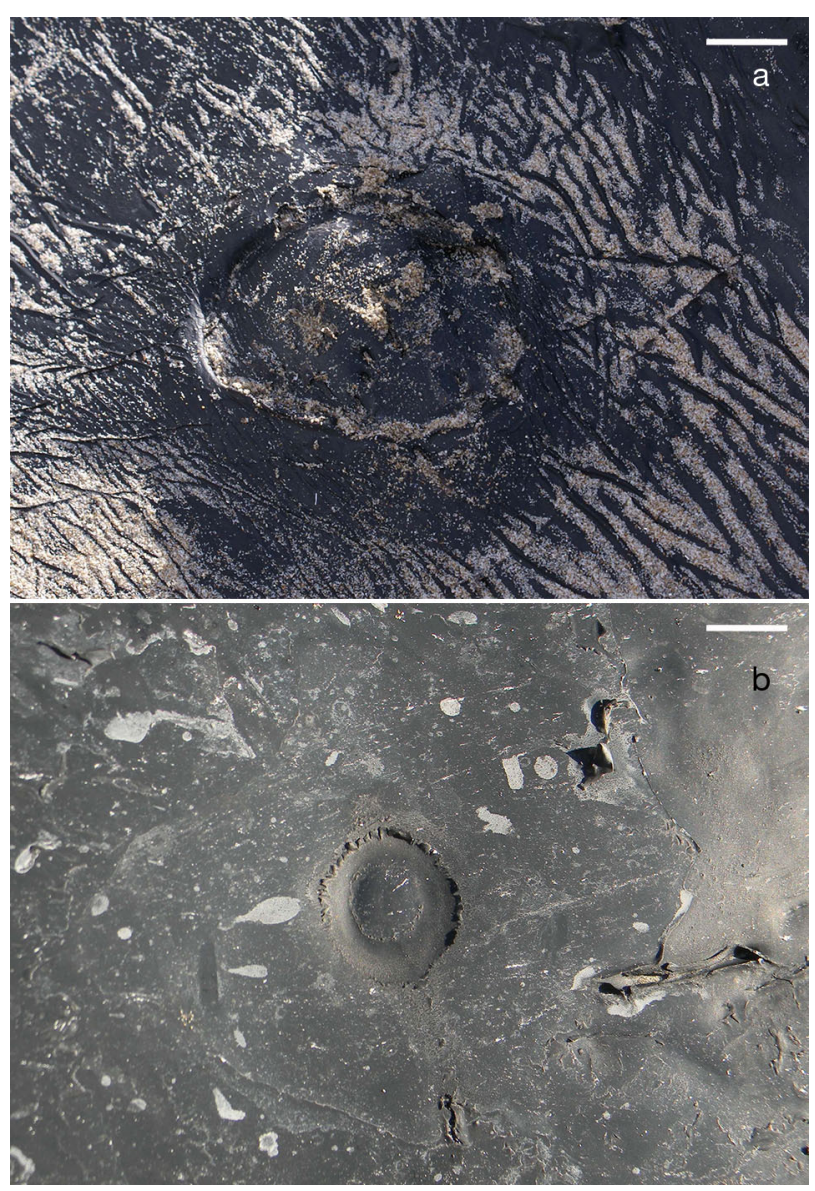

Fig. 1. Macroscopic morphology of cutaneous lesions in Eubalaena australis: (a) calf, sample BFA-04/12; and (b) adult, sample BFA-01/13. Both were ring-type lesions, with a raised center. The calf lesion is more proliferative. Scale bars $=2 \mathrm{~cm}$ 

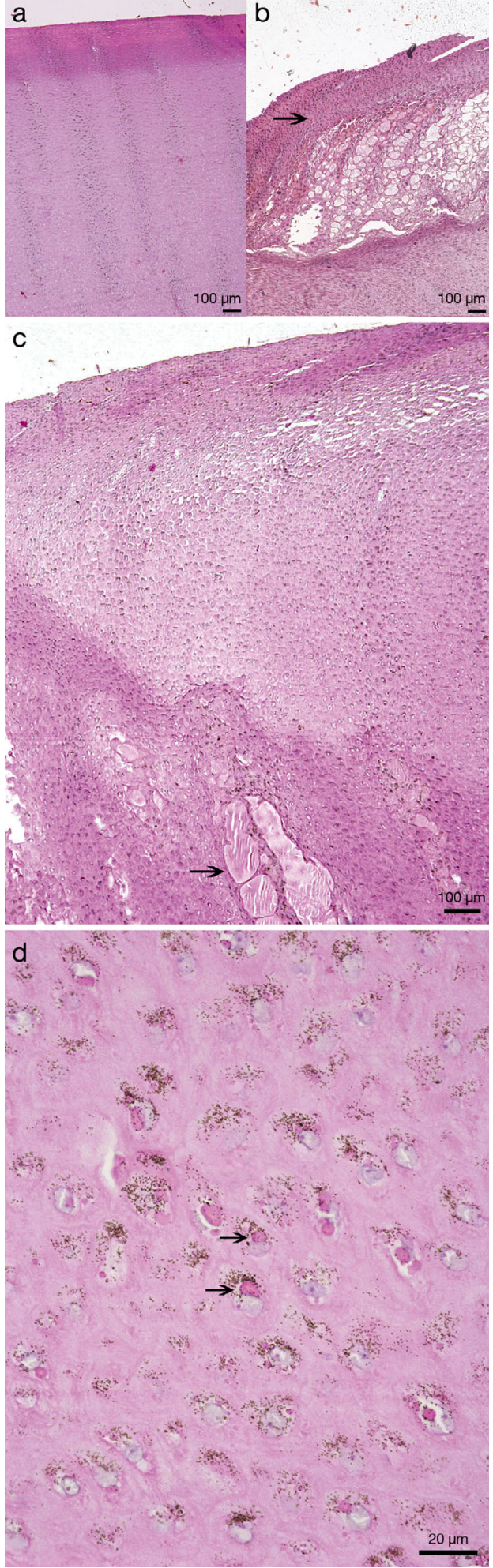

Fig. 2. Microscopic morphology of cutaneous lesions in Eubalaena australis. Hematoxylin and eosin stained. (a) Portion of normal skin adjacent to the lesion (50x). (b-d) Sections through the edge of ringtype lesion: (b) areas of hyperplasia (arrow) (50x); (c) microvesicles (arrow) and pale vacuolate area $(50 \times)_{i}(d)$ eosinophilic intracytoplasmic inclusion bodies in infected stratum intermedium cells (arrows) (400x) showed the presence of microvesicles and vacuolated cells present in the stratum spinosum along with areas of hyperplasia (Fig. 2). Numerous eosinophilic inclusion bodies were visualized in the cytoplasm of epithelial cells (Fig. 2). The dermis had lymphocytic inflammatory infiltrate, which extended into the deep region, affecting blood vessels (vascular arteritis). Dermal papilla were dilated, congestive, and infiltrated with inflammatory cells (not shown).

\section{TEM analysis}

Poxvirus presence was confirmed by TEM in one sample (BFA-04/12). Virion aggregations at various stages of development were observed. Mature particles could be recognized as electron-dense bodies of uniform ellipsoidal shape, approximately $150 \mathrm{~nm}$ in diameter by 200-320 nm in length, with a nucleus or internal biconcave core (dumbbell-shaped), an outer membrane, an intermediate coat and an outer envelope (Fig. 3).

\section{PCR amplification and phylogenetic results}

Fragments of CPV DNA polymerase and DNA topoisomerase I genes were amplified from the BFA01/13 skin lesion sample (Fig. 4). In addition, the housekeeping ND1 fragment of $560 \mathrm{bp}$ also generated a product of the expected size. The PCR assay for parapoxvirus DNA polymerase was negative (not shown).

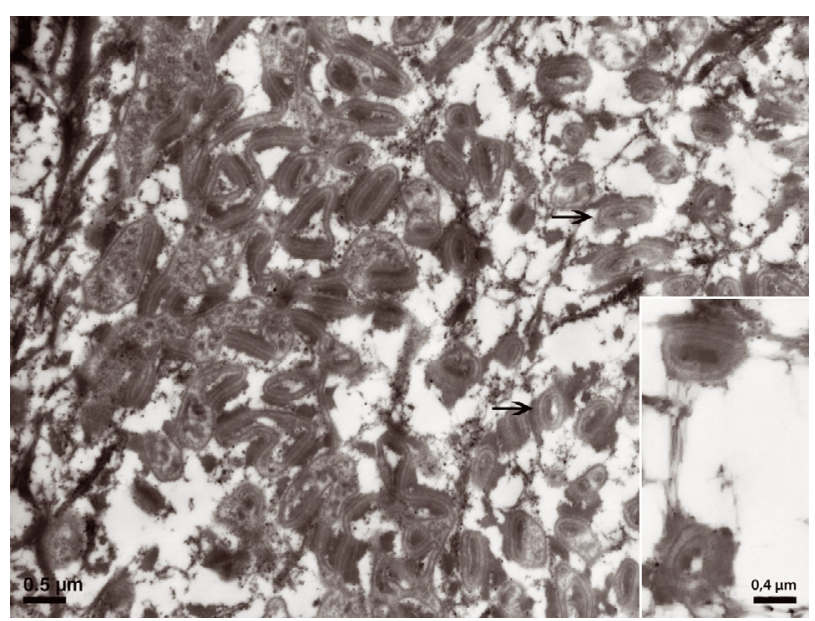

Fig. 3. Transmission electron microscopy of ring-type lesion in Eubalaena australis. Dumbbell-shaped cores surrounded by lateral bodies and enclosed by an outer membrane are visible in mature virions (arrows). Scale bar $=0.5 \mu \mathrm{m}$. Inset: magnification of virions 


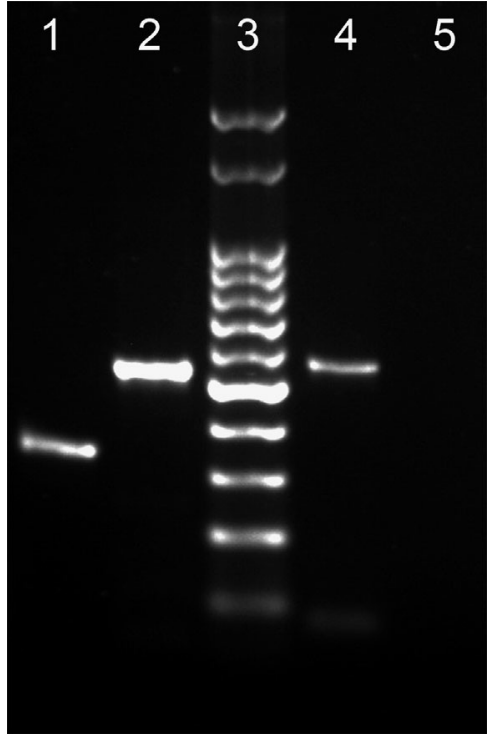

Fig. 4. Cetacean poxvirus (CPV)-specific PCR assay and agarose gel electrophoresis of amplified DNA fragments. Lane 1: CPV-2 DNA topoisomerase I gene fragment; Lane 2: CPV-2 DNA polymerase gene fragment; Lane 3: DNA ladder (100 bp; PB-L, Argentina); Lane 4: Eubalaena australis $\mathrm{NADH}$ dehydrogenase subunit 1 gene (ND1) fragment (560 bp); Lane 5: negative control

In the ML phylogenetic trees obtained from the DNA polymerase, DNA topoisomerase I and concatenated datasets, the BFA-01/13 and the only CPV-2 sequence previously reported (Bracht et al. 2006) formed a monophyletic cluster with high statistical support (Fig. 5; Figs. S1 \& S2 in the Supplement at www.int-res.com/articles/suppl/d116p157_supp.pdf); similar results were obtained in the NJ and Bayesian analysis (data not shown). The BFA-01/13 and the CPV-2 DNA polymerase sequences shared $94.5 \%$ in nucleotide and $97.6 \%$ in deduced amino acid identities. For the DNA topoisomerase I sequence identities, these values were $92.4 \%$ and $94.0 \%$ respectively.

\section{DISCUSSION}

This study provides the first evidence to our knowledge of poxvirus skin lesions in southern right whale in Argentina. Although the study has a number of limitations, particularly a small number of samples and the autolysis level of specimens, the presence of the virus was confirmed by histopathology in both individuals as well as by electron microscopy in sample BFA-04/12 and PCR assay in BFA-01/13.
Samples analyzed in this report showed a macroscopic aspect similar to previously described lesions in northern right whales (Hamilton \& Marx 2005) and southern right whales (Bertellotti et al. unpubl. rep.), and also similar to bowhead whale lesions from Alaska (C. Rosa et al. unpubl. rep.). PSD confirmation and its comparison with photographic images is a potentially useful tool, since PSD morphology would be visually distinguished from other skin disorders (Blacklaws et al. 2013). Future research should be orientated to enlarging sample size and measuring the sensitivity and specificity of visual diagnosis of PSD. This is a necessary step because visual diagnosis could make it possible to study and understand aspects of the disease in free-ranging southern right whales. Our histological analysis is comparable to skin lesions described in other reports involving cetacean poxvirus (Geraci et al. 1979, Baker 1992, Van Bressem et al. 1999). The presence of eosinophilic intracytoplasmic inclusion bodies in epidermal cells and the observation of poxvirus-like particles by TEM supports this diagnosis. However, while these techniques are useful in confirming both the presence of typical microscopic poxvirus lesions as well as the visualization of viral particles in cetacean lesions, they do not permit species-specific or even group-specific identification. This report confirmed the presence of $\mathrm{CPV}$ in skin lesions of one southern right whale by PCR and sequence determination. The phylogenetic analysis and the high identities observed in the DNA polymerase and DNA topoisomerase I sequences (both nucleotide and amino acid) revealed that the CPV described here is closely related to the CPV-2 previously detected in skin lesions of a Balaena mysticetus sampled in Alaska (Bracht et al. 2006). Those authors proposed that CPV-2 should be classified as a new subgroup into the Chordopoxvirinae subfamily. In the present work, according to the findings in $\mathrm{Eu}$ balaena australis, such as the lesion morphology, the virion architecture and the phylogenetic relationships, it is most likely that CPV-2 is a mysticetes suborderspecific virus, belonging to a separate genus of cetacean poxviruses.

Further studies of southern right whale skin lesions are ongoing. Establishing the pathogenic agents of disease in cetaceans is a complex task, especially because of the difficult access to quality samples for diagnosis. Increased efforts will be made to collect tissue samples from both live and dead animals for histopathology and ancillary analysis. Finally, further studies are necessary to establish the prevalence and effects of these viruses in the population of southern right whales. 


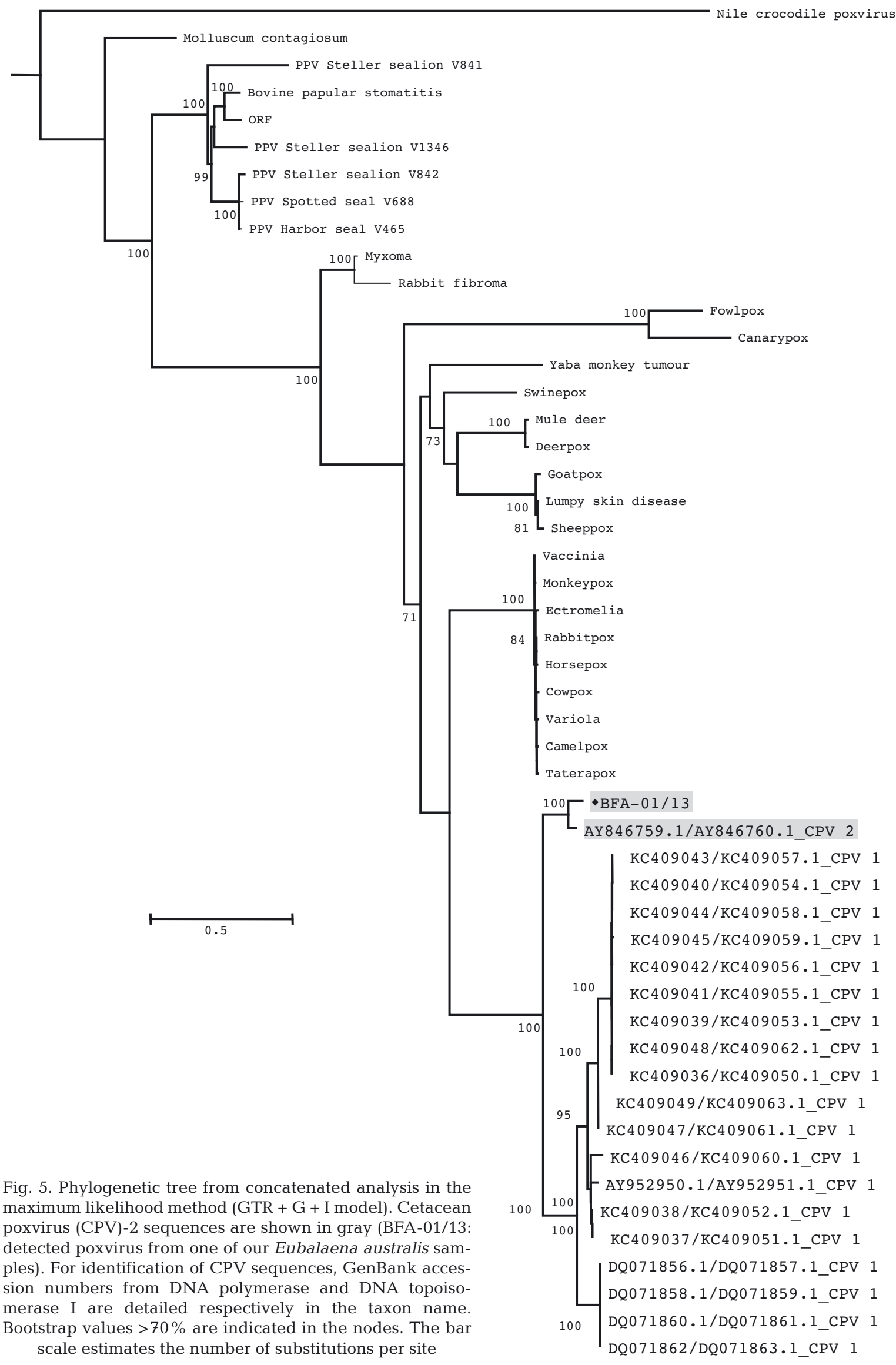


Acknowledgements. We thank the Coastal Wildlife Network of Chubut Wildlife Agency and the Southern Right Whale Health Monitoring Program for reporting the whale strandings. We also thank Dr. Carlos Romero, Pablo Gasaneo, Juan Bobiez, Alejandra Montico, Gabriela Bellazzi, Alejandra Varisco, Clara Carou and Martin Chaparro. All samples were collected by C.F. with annual research permits issued by the Dirección de Fauna y Flora Silvestre and the Subsecretaría de Turismo y Áreas Protegidas of Chubut Province, Argentina (permit numbers 012-SsCyAP/12, 32/2012DFyFS-SSAyG, 047-SsCyAP/13 and 20/2013-DFyFS-MAGByP). This work was supported by UBACyT grants 20112014, University of Buenos Aires, Scientific Programming, Project Code 20020100100907.

\section{LITERATURE CITED}

Baker JR (1992) Skin disease in wild cetaceans from British waters. Aquat Mamm 18:27-32

Blacklaws BA, Gajda AM, Tippelt S, Jepson PD, Deaville $\mathrm{R}_{1}$ Van Bressem MF, Pearce GP (2013) Molecular characterization of poxviruses associated with tattoo skin lesions in UK cetaceans. PLoS ONE 8:e71734

Bracht AJ, Brudek RL, Ewing RY, Manire CA and others (2006) Genetic identification of novel poxviruses of cetaceans and pinnipeds. Arch Virol 151:423-438

Fazio A, Bertellotti M, Villanueva C (2012) Kelp gulls attack southern right whales: a conservation concern? Mar Biol 159:1981-1990

Fazio A, Argüelles B, Bertellotti M (2015) Change in southern right whale breathing behavior in response to gull attacks. Mar Biol 162:267-273

Geraci JR, Lounsbury VJ (2005) Marine mammals ashore: a field guide for strandings, 2nd edn. National Aquarium in Baltimore, Baltimore, MD

Geraci JR, Hicks BD, St Aubin DJ (1979) Dolphin pox: a skin disease of cetaceans. Can J Comp Med 43:399-404

Editorial responsibility: Michael Moore, Woods Hole, Massachusetts, USA
Hall TA (1999) BioEdit: a user-friendly biological sequence alignment editor and analysis program for Windows 95/98/NT. Nucleic Acids Symp Ser 41:95-98

> Hamilton PK, Marx MK (2005) Skin lesions on North Atlantic right whales: categories, prevalence and change in occurrence in the 1990s. Dis Aquat Org 68:71-82

> Miller MA, Pfeiffer W, Schwartz T (2010) Creating the CIPRES Science Gateway for inference of large phylogenetic trees. In: Proc Gateway Computing Environments Workshop (GCE), New Orleans, LA, 14 November 2010. IEEE, New York, NY

> Posada D (2008) jModelTest: phylogenetic model averaging. Mol Biol Evol 25:1253-1256

Rowntree VJ, McGuinness PM, Marshall K, Payne R, Sironi M, Seger J (1998) Increased harassment of right whales (Eubalaena australis) by kelp gulls (Larus dominicanus) at Peninsula Valdes, Argentina. Mar Mamm Sci 14: 99-115

Tamura K, Stecher G, Peterson D, Filipski A, Kumar S (2013) MEGA6: Molecular Evolutionary Genetics Analysis version 6.0. Mol Biol Evol 30:2725-2729

- Van Bressem MF, Van Waerebeek K, Reyes JC, Dekegel D, Pastoret PP (1993) Evidence of poxvirus in dusky dolphin (Langenorhynchus obscurus) and Burmeister's porpoise (Phocoena spinipinnis) from coastal Peru. J Wildl Dis 29: 109-113

- Van Bressem MF, Van Waerebeek K, Raga JA (1999) A review of virus infections of cetaceans and the potential impact of morbilliviruses, poxviruses and papillomaviruses on host population dynamics. Dis Aquat Org 38:53-65

Van Bressem MF, Van Waerebeek K, Aznar FJ, Raga JA and others (2009) Epidemiological pattern of tattoo skin disease: a potential general health indicator for cetaceans. Dis Aquat Org 85:225-237

Wilson B, Arnold H, Bearzi G, Fortuna CM and others (1999) Epidermal diseases in bottlenose dolphins: impacts of natural and anthropogenic factors. Proc R Soc B 266: 1077-1083

Submitted: November 27, 2014; Accepted: August 20, 2015 Proofs received from author(s): September 29, 2015 